\title{
Evaluating the basic life support knowledge among schoolteachers: A cross-sectional survey in Kayseri, Turkey
}

\author{
Adem Dursun ${ }^{1}$, Serkan Özsoylu1 ${ }^{1}$ Burcu Emeklioğlu², Başak Nur Akyıldız \\ ${ }^{1}$ Intensive Care Unit, ${ }^{2}$ Department of Pediatrics, Erciyes University Faculty of Medicine, Kayseri, Turkey. \\ E-mail:dr.ademdursun@gmail.com.tr \\ Received: 6th January 2018, Revised : 17th February 2018, Accepted : 12th March 2018
}

SUMMARY: Dursun A, Özsoylu S, Emeklioğlu B, Akyıldız BN. Evaluating the basic life support knowledge among schoolteachers: A cross-sectional survey in Kayseri, Turkey. Turk J Pediatr 2018; 60: 702-708.

Children spend a significant proportion of their day in school when they are not with their families.Therefore they might experience medical emergency situations due to injuries, complications of chronic health conditions, or unexpected major illnesses that occur in school. In cases of emergencies, school teachers are expected to play a key role in performing basic life support (BLS) on school children. Very limited data are present in the literature that address the knowledge of the schoolteacher regarding BLS. The primary objective of this study was to asses the BLS knowledge, training status and attitude towards pediatric BLS among schoolteachers.

The study had a cross-sectional research design and was conducted between January and March 2017. A self administered questionnaire was used for data collection to assess the knowledge of teachers.

The questionnaires were filled in by 541 teachers ( 243 male and 298 women). The median age of the study population was 39 (34-45) years. One-third of the respondents reported having taken a BLS class in the past $(33.1 \%)$. The mean for the correct answers for the study population was 5/14 (4/14-7/14). For trained teachers, it was $6 / 14(4 / 14-8 / 14)$ and for untrained teachers, it was $5 / 14(3 / 14-7 / 14)(\mathrm{P}<0.001)$. There were no differences between teachers who had attended different BLS courses. Significant differences between teachers were observed: $62 \%$ of teachers with previous BLS training felt capable of providing cardio pulmonary resusitation (CPR) to their students compared to $48 \%$ in the group without previous training $(P=0.001)$. Ninety- five percent of the teachers were eager to attend a BLS course and $92 \%$ reported that BLS training should be mandatorily given for teacher certification.

Teachers are aware of the importance of BLS and they are willing to attend BLS training programs and improve their knowledge.

Despite the fact that the knowledge of trained teachers was found to be better than those of untrained teachers, school teachers in Turkey have a low level of knowledge and skills regarding BLS.

Key words: basic life support, knowledge, teachers.

Out-of-hospital cardiac arrests (OHCA) are the most common type of emergencies not only in the adult population but also in children. Early recognition and prompt basic life support (BLS) may improve the outcome and double or triple the chances of survival. ${ }^{1}$ In the United States, approximately 250,000-350,000persons experience an OHCA each year. However, the survival rate is less than $7 \% .2,3$ This information indicates that the majority of patients do not receive appropriate BLS until experienced medical help arrives. The presence of a person who knows how to perform BLS is critical to increase the survival rates. If $20 \%$ of the population were able to perform prompt BLS, the morbidity and mortality rates could be significantly decreased. ${ }^{4}$ 
Schoolteachers play an important role in the education of future generations and children spend a significant proportion of their day in school when they are not with their families. Generally, the teacher is the first adult person who may be present at the scene of a medical emergency at school. Therefore, teachers take on a special position in children's life. To maximize the number of children with cardiac arrest receiving prompt BLS and to increase the survival rates, it seems that schoolteachers should be in particular prepared for delivering BLS. However, their actual capacity to perform BLS is not known well.

Recently, both the American Academy of Pediatrics (AAP) and the American Heart Association (AHA) have published guidelines stressing the need for school principals to establish emergency-response plans to deal with life-threatening medical emergencies in children. ${ }^{5}$ School teachers are expected to play a vital role in performing cardio pulmonary resuscitation (CPR) on school children in urgent cases. Unfortunately, very limited data is present in the literature which address the level of knowledge of schoolteachers regarding BLS. The aim of the present study is to use published guidelines by the AAP and AHA to examine the level of knowledge, training status and attitude towards pediatric BLS among teachers.

\section{Material and Methods}

\section{Study design and sample selection}

The study had a cross-sectional research design and was conducted between January and March 2017. The study protocol was approved by the Medical Ethics Research Committee at Erciyes University in Kayseri with a number of 2017/322. There are a total of 325 primary schools in 3 (central) towns of Kayseri, and 8200 teachers work in these schools. A selfadministered questionnaire was used for data collection to assess the knowledge of teachers. Questions used in the questionnaire were prepared according to 2015 AHA guidelines. ${ }^{6}$ A stratified random sampling method was used to select participants.

\section{Questionnaires and datacollection}

The data were collected by means of questionnaire forms (supplementary data) which were filled in by the teachers. A 21-point multiple choice questionnaire was developed specifically for this study. A survey consisting of three distinct parts which are:

(1) demographics: three questions (sex, age, marital status);

(2) BLS knowledge level: two questions about previous training and 12 theoretical or skill questions which surveyed familiarity with the current BLS guidelines and 2 scenarios of cardiac arrest depicting real life situations;

(3) attitude towards BLS: 5 questions including whether teachers should be mandated to have BLS training, investigation of their willingness to learn, their confidence and the barriers to perform BLS was conducted.

(4) whether teachers received CPR training: Curriculum of the education faculties were examined to investigate in which branches BLS training is mandatory or elective ${ }^{7}$. In addition, participants were asked a question if they had previously received BLS training and study population was divided in two groups as trained and untrained

The purpose of the study was explained to teachers and the questionnaire was completed by using an interview technique. Correct cardiac arrest signs and BLS procedures were determined according to the AHA and the European Resuscitation Council (ERC) 2015 guidelines.

A scoring system was created, allocating one point to each correct answer, with no negative marking. A total score was given to each participant.

\section{Data analysis}

Statistical analysis was performed using SPSS version 22.0 (IBM, Armonk, NY). The normality of parametric data was analyzed by the Shapiro Wilk test. Numerical variables were expressed as median (Q1-Q3). Comparisons between groups for data that did not show a normal distribution were performed using the MannWhitney $U$ test. Categorical variables were compared using the $x^{2}$ test. A $\mathrm{P}$ value of $<0.05$ was considered statistically significant for all analyses. 


\section{Results}

The questionnaires were filled in by 541 teachers from 20 different primary and secondary schools in Kayseri,which is a city located in central Anatolia, in Turkey. Demographic characteristics of the respondents are shown in Table I. There were 243 men (214 married vs. 29 single) and 298 women (254 married vs. 44 single). The median age of the study population was 39 (34-45) years. For women, it was 38 (33-43) years and for men it was $40(35-48)$ years $(p=0.002)$. There were four age categories; most of the teachers were either aged 31-40 $(n=227,42 \%)$ or $41-50(n=183,34 \%)$. The two other clusters of items in the questionnaire focused on CPR related topics: (1) training status and motivations for learning BLS, (2) CPR knowledge and skills assessment.

\section{Training status andattitude towards BLS}

One-third of respondents reported previously having taken a BLS class $(33.1 \%)$. The training was obtained in various ways for example, as a health ministry course, at an university, during military service, as a part of a driving license course or at work (Table I). It was learned that, these educations were not specific to children. Significant differences between teachers were observed: $62 \%$ of teachers with previous BLS training felt capable of providing CPR to their students compared to $48 \%$ in the group without previous training $(\mathrm{P}=0.001)$, see Table II. There was no relationship between age group and previous BLS training $(\mathrm{p}=0.793)$. Importantly, the attitude towards CPR training was positive. Ninety-five percent of the teachers were eager to attend BLS course. Furthermore, $92 \%$ reported that BLS training should be mandatory for teacher certification.

There were significant differences between trained and untrained teachers regarding their confidence in performing mouth to mouth resuscitation (trained : $36 \%$, untrained: $25 \%$, $\mathrm{p}=0.004$ ), chest compressions (trained: $40 \%$, untrained: $27 \%, \mathrm{p}=0.002$ ) and both procedures together ( trained : $40 \%$, untrained: $27 \%, \mathrm{p}<$ 0.001 ). In the training group $49 / 179$ teachers, and in the non-training group 115/362 teachers, reported that that they did not feel capable of providing any of them $(p=0.172)$.

Participants were asked the barriers to perform BLS; $114 / 179$ trained and 272/362

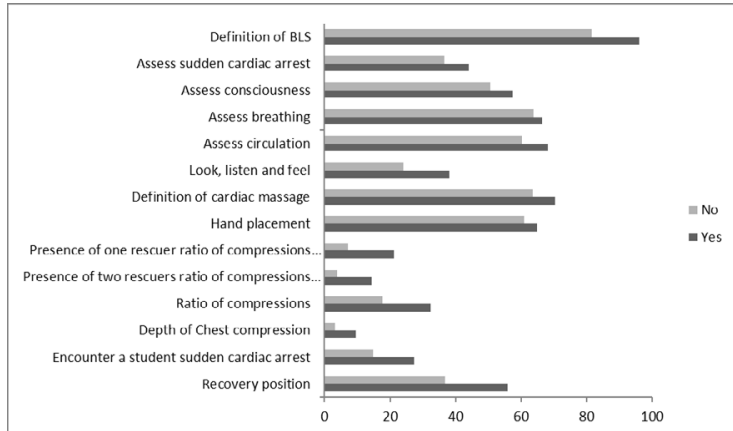

Fig.1. Percentages of correct responses to each question on the basic life support survey in trained and un-trained groups.

untrained teachers reported that conducting CPR incorrectly was a barrier likely to prevent them from performing BLS $(p=0.005)$.

\section{CPR knowledge and skills assessment}

The percentages of correct answers to the knowledge questions and for skill demonstration are provided in Figure I and Figure II. One teacher achieved full marks in the questionnaire and 26 teachers (4.8\%) answered over $70 \%$ $(10 / 14)$ of the questions correctly.Teachers' performance on the knowledge and skills assessment (14 questions) was low. The median for the correct response for the study population was $5 / 14(4 / 14-7 / 14)$. For trained teachers, it was 6/14 (4/14-8/14) and for untrained teachers, it was 5/14 (3/14-7/14). Previous CPR training had a significant effect on the correct responses $(P<0.001)$, however there were no differences between teachers who had attended different BLS courses and significant differences were not observed for knowledge between the different age groups $(\mathrm{P}=0.742)$.

Two cardiac arrest scenarios were presented: In the first one, a student develops cardiac arrest

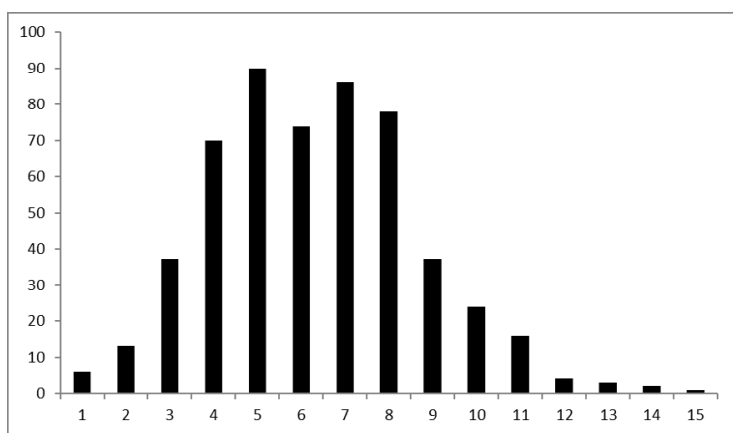

Fig. 2. Frequency of correct responses to questionnaire 
Table I. Demographic Characteristics and Basic Life Support Training Status among Primary and Secondary School Teachers in Kayseri.

\begin{tabular}{lccc}
\hline Characteristics & $\begin{array}{c}\text { Female } \\
\text { (Percent) }\end{array}$ & $\begin{array}{c}\text { Male } \\
\text { (Percent) }\end{array}$ & $\begin{array}{c}\text { Total } \\
\text { (Percent) }\end{array}$ \\
\hline Age & $34(6.2 \%)$ & $22(4 \%)$ & $56(10.3 \%)$ \\
$20-30$ & $132(24.3 \%)$ & $95(17.5)$ & $227(42 \%)$ \\
$30-40$ & $110(20.3 \%)$ & $73(13.4 \%)$ & $183(33.8 \%)$ \\
$40-50$ & $22(4 \%)$ & $53(9.7 \%)$ & $75(13.8 \%)$ \\
$>50$ & & & $73(13.5 \%)$ \\
Marital status & $44(8.1 \%)$ & $29(5.3 \%)$ & $468(86.5 \%)$ \\
Single & $254(46.9 \%)$ & $214(39.5 \%)$ & \\
Married & & & $179(33.1 \%)$ \\
BLS course attendance & $89(16.4 \%)$ & $90(16.6 \%)$ & $362(66.9 \%)$ \\
Yes & $209(38.6 \%)$ & $153(28.2 \%)$ & \\
No & & $12(6.7 \%)$ & $22(12.2 \%)$ \\
Location of BLS course & $10(5.5 \%)$ & $13(7.2 \%)$ & $35(19.5 \%)$ \\
Health Ministry & $22(12.2 \%)$ & $31(17.3 \%)$ & $65(36.3 \%)$ \\
University & $34(18.9 \%)$ & $23(12.8 \%)$ & $49(27.3 \%)$ \\
Driving license & $26(14.5 \%)$ & $12(6.7 \%)$ & $13(7.2 \%)$ \\
School & $1(0.5 \%)$ & & \\
Other & & & \\
\hline
\end{tabular}

Table II. Training Status and Confidence of Performing BLS.

\begin{tabular}{lccc}
\hline Question Title & $\begin{array}{c}\text { Trained } \\
\text { (percentage) }\end{array}$ & $\begin{array}{c}\text { Untrained } \\
\text { (percentage) }\end{array}$ & P value \\
\hline Feel capable to provide BLS to & $110 / 179$ & $172 / 362$ & 0.01 \\
Student & $(61.4 \%)$ & $(47.5 \%)$ & 0.06 \\
Co-worker & $117 / 179$ & $194 / 362$ & $(53.5 \%)$ \\
Family member & $(65.3 \%)$ & $254 / 362$ & 0.236 \\
Stranger in a supermarket & $143 / 179$ & $(72.1 \%)$ & $<0.001$ \\
A person at the bus stop with bad personal & $(79.8 \%)$ & $77 / 362$ & 0.006 \\
& $64 / 179$ & $(21.2 \%)$ & 0.001 \\
A homeless drug addict & $(35.7 \%)$ & $67 / 362$ & 0.011 \\
Anybody & $(28.4 \%)$ & $(18.5 \%)$ & 0.017962 \\
\end{tabular}

due to respiratory failure when no one is there except the teacher. The results were as follows: $48.8 \%$ of interviewees stated thatthey would call Emergency Medical Services (EMS) and then start to resuscitate the victim. Nineteen percent responded correctly that they would start to resuscitation and then call EMS, $1.9 \%$ stated that they did not know what to do in such a situation, $9.8 \%$ said they would call EMS and would not start to resuscitation, $6.8 \%$ would notify the school principal and would not start resuscitation and $4.6 \%$ would notify the school headmaster and start to resuscitation. Concerning the recovery position, participants 
were presented another scenario. When the vital reflexes returned in a student on whom BLS was performed, participants were asked which body position would they put the student in to avoid any aspiration and tongue rolling? In response, $43.1 \%$ of the participants stated correctly that they would put a person in cardiac arrest in the recovery position, $22.4 \%$ of the teachers would not change the position and wait for EMS, $3.9 \%$ selected the prone position and $30.7 \%$ of them stated that they did not know what to do in such a situation.

\section{Discussion}

Teachers are responsible for the physical wellbeing of a large proportion of the nation's children for many hours each day and they are expected to play a vital role in the care of on school children in urgent cases. ${ }^{8}$ In a survey of school nurses, Sapien and Allen ${ }^{9}$ reported that $67 \%$ of schools have activated EMS over the past year for a life-threatening emergency in a student, with an average of 4 transports per year. Seventeen percent of surveyed public school teachers in midwestern states reported at least 1 life-threatening student emergency during their teaching career. ${ }^{10}$ Recently published guidelines recommended to improve the training of school nurses to determine rapidly and accurately life-threatening emergencies.Additionally, 2 or more members of the school staff should be educated to handle emergencies until the nurse, physician or other emergency personnel can be contacted since school health nurses or physicians cannot always be available. ${ }^{11}$ These studies stress the importance of establishing BLS knowledge and skills among teachers. The present study is the first to investigate a critical issue namely that school teachers in Turkey have a low level of knowledge and skills regarding BLS.

The AHA suggested that at least $20 \%$ of adults need to be trained in CPR in order to decrease morbidity and mortality from OHCA significantly. ${ }^{4}$ In order to target as many young people as possible, schools are ideal places to teach BLS. At the beginning of the sixties, CPR training was first included in the curriculum of high school students in Norway. ${ }^{12}$ Later, many other European countries developed school CPR training programs. In Flanders, Belgium, CPR became part of the secondary school curriculum in September 2010.13 In Turkey, CPR training is still not part of the school curriculum but it is mandatory for physical education teacher certification and elective for teachers in other branches. ${ }^{7}$

The BLS course is also given in the military service and driving license courses. These courses are not specific to children.However, this study found that only one-third of the teachers have taken courses or received information about BLS. The studies performed in Greece and Saudi Arabia had similar findings to ours and showed that school teachers lack CPR training. ${ }^{14,15}$ However, our result was very low when compared with a study in Belgium which reported that $59 \%$ of teachers had received BLS training. ${ }^{13}$

In our study, teachers were aware of the importance of BLS. Most of the participants agreed that BLS is an important part of their professional education and more than $90 \%$ of the them reported that it should be mandatory to undergo BLS training for teacher certification. Similar studies have assessed teachers' willingness to take CPR courses. When compared with other studies, the participants in our study were more eager than others. A study among school teachers in Riyadh performed by Alharbi et al. ${ }^{16}$ Demonsrated that $53 \%$ of teachers supported mandatory training for their teacher certifications. In a Flemish, study Mpotos et al. ${ }^{13}$ stated that $73 \%$ of teachers would like to receive more CPR training. BLS training was shown to result with an improvement in knowledge and skill of CPR. ${ }^{17}$ In order to improve the survival rates from cardiopulmonary arrest in schools, as seen in other countries, BLS training should be mandatory in Turkey not only for teachers but also for students, specifically in secondary schools and high schools.

Time is critical when helping a person in cardiopulmonary arrest. BLS involves a systematic approach to diagnose cardiopulmonary arrest, activation of emergency medical services and the initiation of resuscitation. AHA recommends that after verifying the scene safety, cardiopulmonary arrest be diagnosed within 10 seconds. 6 Therefore the most important factor for a BLS provider is to be sure of on the cardiac arrest diagnosis. However, this study revealed 
that the majority of teachers $(n=330,61 \%)$ did not correctly identify cardiac arrest. In case of cardiac arrest, another important aspect is the early activation of the emergency medical service. Rescuers should learn how and when to call the EMS. In this study, participants were presented a scenario in which a student develops cardiac arrest due to respiratory failure. However, in their responses $81 \%$ of the participants said that they would call for help before trying to resuscitate the victim. This indicates that most of the participants do not know exactly when to call the EMS for help. The present study also revealed that the school teachers had inaduquate BLS knowledge. One possible explanation might be that lower numbers of teachers have previously attended training courses. The mean for the correct response for the study population was $5 / 14(4 / 14-7 / 14)$. Only one teacher achieved full marks in the questionnaire and $4.8 \%$ $(n=26)$ of them answered $70 \%(10 / 14)$ of the questions correctly. These findings are in agreement with those of previous studies which have consistently shown poor BLS knowledge among teachers. ${ }^{18,19}$

Training helps people to learn the skills and develop the confidence to provide CPR when encountering a cardiac arrest victim. ${ }^{6}$ Another key area of this study was the effect of training status on participants' knowledge and confidence to perform BLS. The rate of answers for trained teachers was 6/14 (4/14-8/14) and for untrained teachers it was 5/14 (3/14$7 / 14)$. Although both trained and untrained teachers had inadequate knowledge, contrary to a previous study ${ }^{19}$, trained teachers achieved significantly higher scores than untrained ones. In our survey only $52 \%$ of teachers felt capable of performing BLS on their students, the majority of the participants (79\%) did not feel capable of performing mouth to mouth resuscitation, chest compressions, and both procedures together. There were significant differences between trained and untrained teachers regarding their confidence. These findings highlight that the continuity of training programs is important since it has been reported that even those who are trained are likely to forget what they have learned and lose their skills ${ }^{20}$. Therefore, we recommend that BLS training programs should be repeated annually or biannually to refresh teachers' knowledge and to increase their confidence to perform BLS.

There are some limitations to our study. The primary limitation is that, it was a singlecenter study and although we were able to obtain survey results ' data on a large number of Kayseri primary and secondary schools, there were a number of schools which are not represented from very small or rural areas. One further limitation is that, our study covers only government schools. A larger sample size that involves various urban and rural schools across Turkey and private schools would reflect the problem more accurately. Finally, this was a cross sectional study and does not have any follow up data.

Teachers are aware of the importance of BLS and they are willing to attend BLS training programs and improve their knowledge. Despite the fact that the knowledge of trained teachers was found to be better than those of untrained teachers, the mean of trained teachers was not satisfactory. We recommend a national plan to reconsider the competency level of teachers and to provide a regular (re)training of BLS knowledge and skills in this curriculum area. We also recommend that BLS training programs should be included in secondary school and high school curricula since this could provide adequate support for society.

\section{Acknowledgements}

We are grateful to all the teachers included in the survey, to all the participating schools and to theTurkish Ministry of National Education for their support.

\section{Supplementary data is available at:}

http://www.turkishjournalpediatrics.org/ uploads/turkjped. 2018.06.011.S1.pdf

\section{REFERENCES}

1. Almesned A, Almeman A, Alakhtar AM. et al. Basic life support knowledge of healthcare students and professionals in the Qassim University. Int J Health Sci (Qassim) 2014; 8: 141-150.

2. Sanna T, La Torre G, de Waure C, et al. Cardiopulmonary resuscitation alone vs. cardiopulmonary resuscitation plus automated external defibrillator use by nonhealthcare professionals: A meta-analysis on 1583 cases of out-of-hospital cardiac arrest. Resuscitation 2008; 76: 226-232. 
3. Atwood C, Eisenberg MS, Herlitz J, Rea TD. Incidence of EMS-treated out-of-hospital cardiac arrest in Europe. Resuscitation 2005; 67: 75-80.

4. Lester C, Donnelly P, Weston C, Morgan M. Teaching schoolchildren cardiopulmonary resuscitation. Resuscitation 1996; 31: 33-38

5. Olympia RP, Wan E, Avner JR. The preparedness of schools to respond to emergencies in children: A national survey of school nurses. Pediatrics 2005; 116: e738-e745.

6. Atkins DL, Berger S, Duff JP, et al. Part 11: Pediatric Basic Life Support and Cardiopulmonary Resuscitation Quality: 2015 American Heart Association Guidelines Update for Cardiopulmonary Resuscitation and Emergency Cardiovascular Care. Circulation 2015; 132(Suppl 2): 519-525.

7. https://www.yok.gov.tr/kurumsal/idari-birimler/ egitim-ogretim-dairesi/yeni-ogretmen-yetistirme-lisansprogramlari

8. Lotfi K, White L, Rea T, et al. Cardiac arrest in schools. Circulation 2007; 116: 1374-1379.

9. Sapien RE, Allen A. Emergency preparation in schools: A snapshot of a rural state. PediatrEmerg Care 2001; 17: 329-333.

10. Gagliardi M, Neighbors M, Spears C, Byrd S, Snarr J. Emergencies in the school setting: Are public school teachers adequately trained to respond? Prehosp Disaster Med 1994; 9: 222-225.

11. American Academy of Pediatrics. Committee on School Health. American Academyof Pediatrics: Guidelines for emergency medical care in school. Pediatrics 2001; 107: 435-436.

12. Lind B, Stovner J. Mouth-to-mouth resuscitation in Norway. JAMA 1963; 185: 933-935.
13. Mpotos N, Vekeman E, Monsieurs K, Derese A Valcke M. Knowledge and willingness to teach cardiopulmonary resuscitation: A survey amongst 4273 teachers. Resuscitation 2013; 84: 496-500.

14. Al Enizi BA, Saquib N, Zaghloul MS, Alaboud MS, Shahid MS, Saquib J. Knowledge and Attitudes about Basic Life Support among Secondary School Teachers in Al-Qassim, Saudi Arabia. Int J Health Sci (Qassim) 2016; 10: 415-422.

15. Patsaki A, Pantazopoulos I, Dontas I, Passali C, Papadimitriou L, Xanthos T. Evaluation of Greek high school teachers' knowledge in basic life support, automated external defibrillation, and foreign body airway obstruction: Implications for nursing interventions. J EmergNurs 2012; 38: 176-181.

16. Alharbi MM, Horaib YF, Almutairi OM, et al. Exploring the extent of knowledge of CPR skills among school teachers in Riyadh, KSA. J Taibah Univ Med Sci 2016; 11: 497-501.

17. Chaudhary A, Parikh H, Dave V. Current scenario: Knowledge of basic life support inmedical college. Natl J Med Res 2011; 1: 80-82.

18. Ghrayeb FA, Amro NRN, Rahseed O, Yagi H, Amro R, Amro B.Knowledge and attitude of basic life support (BLS) among school teachers in Hebron, Palestine. Int J Res Med Sci 2017; 5: 2477-2482.

19. Al Enizi BA, Saquib N, Zaghloul MS, Alaboud MS, Shahid MS, Saquib J. Knowledge and Attitudes about Basic Life Support among Secondary School Teachers in Al-Qassim, Saudi Arabia. Int J Health Sci (Qassim) 2016; 10: 415-422.

20. Abbas A, Bukhari SI, Ahmad F. Knowledge of first aid and basic life support amongst medical students: A comparison between trained and un-trained students. J Pak Med Assoc 2011; 61: 613-616. 